malignant or fulminant varieties of catatonia, the use of electroconvulsive treatment is warranted, and at times, lifesaving. Indeed, the association of catatonia with schizophrenia and the automatic administration of neuroleptic drugs is not only rarely helpful but is associated with worsening of the syndrome (Fricchione et al, 1983).

This child may have been improperly classified; if so, the prolonged illness and poor outcome may have been avoided by a consideration of this diagnosis and its treatment early in the course.

A full list of references is available from the authros on request.

Fricchione, G. L., CASSEm. N. H., HoOberman, D., et al (1983) Intravenous lorazepam in neuroleptic induced catatonia. C Clin Psychopharmacol 3. 338-342.

TAYLOR, M. A. (1990) Catatonia. A review of the behavioral neurologic syndrome. Neuropsychiat. Neuropsychol. \& Behav. Neurol. 3, 48-72.

Whrte, D. A. C. \& RoBins, A. H. (1991) Catatonia: Harbinger of the neuroleptic malignant syndrome. $\mathrm{Br} J$ Psychiatry $158,418-421$.

MAX FINK and Donald F. KLEIN, State University of New York at Stony Brook, PO Box 459, St James, New York 11780, USA

Sir: In their letter, Fink \& Klein make the interesting diagnostic suggestion that the case we described in our article suffered post-viral encephalitis with residual catatonia. As the case details were only intended to provide sufficient information to illustrate a number of ethical dilemmas, some of the data less relevant to these issues were omitted. Let me provide them now.

First, the child was thoroughly investigated in a neuro-surgical unit before admission to us, and re-assessed by our own neurological department while under my care. No evidence of neurological impairment was detected. Second, the child showed no evidence of specific catatonic features at any time. She had the non-specific feature of double incontinence, but no waxy flexibility or any of the characteristic peculiarities of voluntary movement.

Fink and Klein's therapeutic suggestions are more surprising. This girl recovered from her marked pervasive refusal within three months without medication. Dedicated nursing care was sufficient to achieve this result. Her residual symptoms consisted of extreme anger with her parents and an eating disorder.
Benzodiazepines did not seem indicated. The symptoms she showed would surely not have warranted electro-convulsive therapy in an adult, let alone an eight-year-old child.

In our article, we did not provide a DSM-IV diagnosis, and perhaps we should have done, although in my experience, as in that of Leo Kanner, the disorders shown by many children who come to psychiatric attention suggest the children have not read the classification books (Kanner, 1969). I think the least inappropriate diagnosis would have been Conversion Disorder, with Dissociative Disorder as the main differential. As noted in the article however, we preferred to use the 'local' diagnosis of Pervasive Refusal Syndrome (Lask et al, 1991) because it is accurately descriptive and carries no unjustifiable aetiological or psychodynamic assumptions.

KANNER, L. (1969) The children haven't read those books: reflections on differential diagnosis. Acta Paedopsychiatrica, 36, 2-11.

LASK. B. BRTTEN, C. KROL. L., et al (1991) Children with pervasive refusal. Archives of Diseases of Childhood. 66. 866-869.

Philip Graham, 27 St Albans Road, London NW5 1RG

\section{The pitfalls of audit for the psychiatric trainee}

Sir: Despite being encouraged to spend time on audit, I found this activity to be fraught with difficulties. My experience stems from conducting an audit of patient satisfaction on an acute adult psychiatric ward. Following my first survey, quality standards were agreed on and recommendations for change were made. The survey was repeated one year later, by which time I was working in another district.

The response to the first survey was encouraging, with 50 questionnaires being completed within four months $(74 \%$ of all patients discharged). But the following year it took five months to get 39 questionnaires completed (41\% of all patients discharged) and, half way through the second survey, it became apparent that the majority of patients were being discharged without being given a questionnaire. I resorted to posting questionnaires to the home address of recently discharged patients, rather than abandoning the audit completely. The poor response to the second survey and necessary 
change of method made it difficult to draw valid conclusions.

Such problems may be familiar to other trainees who have rotated into new posts by the time they reach the second stage of an audit. Other staff that have to be relied on in the absence of the trainee may be less well motivated and unclear as to the nature of the project. This can result in difficulties obtaining data and problems in interpreting it. Recommendations for change that may be enthusiastically made initially, assume a lower priority than day to day patient management issues unless their importance is repeatedly reinforced.

The difficulties encountered by rotating doctors wishing to gain audit experience would be reduced if each hospital and specialty could agree on a regular rolling programme of audit (Shaw \& Costain, 1989). Involvement of the local clinical audit service may be helpful in setting this up. Whilst emphasis is placed on the importance of 'closing the loop' by repeating the examination of data in six months or a year, this usually creates problems for the trainee and often means projects being started by one person and completed by another (Cook \& Langa, 1994). Time allocated to audit for the trainee might enable projects to be successfully completed despite job moves rather than abandoned, as often happens at present. Trainees are likely to continue to be frustrated by the audit process until sufficient time and back-up are made available.

COOK. A. \& LANGA. A. (1994) A trainee's view of basic issues in audit. Psychiatric Bulletin. 18, 477-479.

Shaw, C. D. \& Costain, D. W. (1989) Guidelines for medical audit: seven principles. British Medical Journal, 299. 498-499.

GILL SALmon, Child and Family Psychiatric Service, Brookside Clinic, Aylesbury, Bucks HP2O 2SQ

\section{Psychiatrists in management}

Sir: I wish to draw to the attention of the College an exceedingly worrying obstacle to the involvement of consultant psychiatrists in management.

During negotiations with our trust management concerning the post of medical director we agreed that the director should have six-ring fenced sessions in which to perform his or her duties - the staff side would, in fact, have preferred eight. We then realised that such a medical director would lose mental health officer status for the duration of his or her appointment and that, in fact, any consultant who has mental health officer status would lose it if he or she engaged in more than two sessions of managerial work.

Clinical directorships possibly, in small trusts, can be done in two sessions but in our case, being a mental health trust covering a population of half a million, two sessions would be hopelessly inadequate.

My purpose in writing is two-fold. First, to draw to the attention of Members and Fellows, this potential threat to their pension rights for every year served as a medical manager with three or more sessions devoted to managerial work there will be a need to work a year extra beyond the expected retirement age and this needs to be borne very carefully in mind by those tempted to apply for such posts. Second. I believe it is the duty of the College to take this matter up with the Department of Health and the pensions agency since it represents a disincentive specific to psychiatrists and of confounding proportions, to them becoming involved in management in anything other than a minor role. This disadvantages psychiatrists and psychiatry. It is. I would suggest, also a quite irrational position for the pensions agency to take since, if anything, being a medical manager of a psychiatric trust is more rather than less stressful than patient contact for which, of course, the mental health officer arrangements were designed to compensate.

D. R. DAviES, Avalon Somerset NHS Trust, Rydon House, Cheddon Road, Taunton TA2 TAZ

Editorial note. See also 'NHS superannuation regulations'. Psychiatric Bulletin, 1994, 18, 713 and letters from Dr Ian G. Bronks and Dr M. J. Harris, Psychiatric Bulletin. 1995, 19. 323-324. 